\title{
Can Exposure to Second-Hand Cannabis Smoke be Harmful?
}

\author{
Tegbir Kaur ${ }^{1}$, Helen Heacock ${ }^{2}$ \\ ${ }^{1}$ Lead Author, B.Tech Student, School of Health Sciences, British Columbia Institute of Technology, 3700 Willingdon Ave, \\ Burnaby, BC V5F $3 \mathrm{H} 2$ \\ ${ }^{2}$ Supervisor, School of Health Sciences, British Columbia Institute of Technology, 3700 Willingdon Ave, Burnaby, BC V5F 3H2
}

\begin{abstract}
Background: Canada legalized the use of cannabis for recreational purposes in October 2018. To ensure public health and safety, the Cannabis Act was also introduced by the Government of Canada in 2018. This Act does not permit smoking cannabis in restricted areas. However, people still smoke in public places, thus, exposing the general public to second-hand cannabis smoke (SHCS). As cannabis is an emerging topic and the legalization of cannabis for recreational use is still recent, the long-term health effects of SHCS is unknown. However, the perceived immediate health impacts of SHCS can be examined to better understand its long-term health effects on human body.

Methods: An online survey was conducted, targeting residents of British Columbia (Canada) with differing smoking status, gender, education level and age groups, to determine the differences in perceived immediate health impacts and/or concerns from exposure to SHCS. The survey consisted of sixteen questions divided into three sections, covering demographic information, exposure to SHCS and perceived immediate health impacts and/or concerns about SHCS. The data was analyzed using Chisquare tests.

Results: A total of 159 participants took part in this survey. The results showed no associations between exposure to SCHS and perceived immediate health impacts. This could be due to the legalization of cannabis for recreational use being so recent. However, headaches, coughing, chest tightness and irritation to eyes are a few perceived immediate health impacts experienced by 41 out of 139 participants (30\%) after exposure to SHCS. This study also found that age and place of exposure may not affect the likelihood of experiencing perceived immediate health impacts. However, females and cannabis nonusers are more likely to experience perceived immediate health impacts compared to males and cannabis users, with $\mathrm{p}=0.01$ and 000003 , respectively.

Conclusion: The findings of this study identified a few perceived immediate health impacts associated with SHCS such as headaches, coughing, chest tightness and eye irritation. However, the study indicates that there is an inadequate scientific knowledge regarding the long-term health effects from exposure to SHCS as well as the variation in health effects among different age groups, gender, smoking status and place of exposure. As a result, precautionary steps should be taken now to minimize its ill-effects in future. The government should provide tools to aide researchers and health care professionals to conduct in-depth research on SHCS and its health effects. Moreover, initiatives should be taken to educate general public about cannabis smoke, its composition, associated health effects and legislation.
\end{abstract}

Keywords: Cannabis, Cannabis smoke, Second-hand cannabis smoke, Smoking, health impact, Environmental Health, Public Health 


\section{Introduction}

To pave the way for legalization of cannabis for recreational purposes, the Government of Canada introduced the Cannabis Act in 2018 (Cannabis Act, 2018). The purpose of this Act is to protect public health. Although the legislation does not permit smoking cannabis in restricted areas, people still smoke in public places, thus exposing the general public to second-hand cannabis smoke (SHCS). Since the study of long-term health effects of second-hand cannabis smoke (SHCS) is still under way and will take another few years, it is important to understand the perceived immediate health impacts and concerns people may have after exposure to SHCS. Knowledge acquired from this study can help scientists and clinicians in medicine and public health to carry out further research to understand the potential health effects of second-hand cannabis smoke. It can also help in implementing educational and policy initiatives to protect non-smokers from second-hand cannabis smoke.

\section{Literature Review}

\section{Background Information}

Cannabis use can be traced back to ancient cultures and continues in our present society. Probably one of the oldest plants, it was cultivated for fibre, food and medicine thousands of years ago (Schultz, 1973). However, at the present time, cannabis is known primarily as one of the leading psychoactive plants in world use. According to Leung (2011), cannabis is mostly used as a therapeutic agent to alleviate chronic and neuropathic pain. The active ingredient, $\Delta 9$-tetrahydrocannabinol (THC) accounts for both the physical and psychotropic effects of cannabis. In addition to THC, it also contains at least 65 other cannabinoids (Rosenthal, 2002). Besides its use as a medicinal drug, cannabis use has also gained popularity for recreational purposes and can be consumed in different ways. According to National Institute on Drug Abuse (NIDA, 2019), it can be consumed by smoking, vaporizing, within food or as an extract.

\section{Prevalence of Cannabis use in Canada}

In Canada, the prevalence of cannabis use has increased markedly over the past few decades. A study was carried out by Rotermann and Pagé in 2018 (Rotermann \& Pagé, 2018) to understand the prevalence of cannabis use in Canada and the characteristics of cannabis users. Data from the 2015 Canadian Tobacco, Alcohol and Drugs Survey (CTADS) was used to estimate prevalence and examine factors associated with people who reported using cannabis for Non-Medically Only (NMO) compared to people who reported Self-Defined Medical and Non-Medical use (SDMNM). The results showed that about $9.2 \%$ of Canadians aged 15 or older reported NMO cannabis use whereas $2.8 \%$ reported SDMNM use. It also concluded that cannabis users are most likely to be male and younger, those who use other illicit drugs, daily smokers or heavy drinkers. Another similar study was published in 2018 by Rotermann and MacDonald (Rotermann \& MacDonald, 2018), before the legalization of cannabis for recreational purposes. In this study, nine national household surveys about cannabis use during the period from 1985 and 2015, were examined for comparability to analyze the trends in the prevalence of cannabis use in Canada. All nine surveys had the same basic target population i.e. household residents aged 15 or older. The results showed that since 2004, the prevalence of cannabis use remained stable or decreased among 15- to 24-year old but increased among people aged 25 or older. However, the overall prevalence of cannabis use 
is higher among 15- to 24-year old as compared to people $>25 y$ rs old. Moreover, the study showed that males are more likely to use cannabis than females. Therefore, both studies show a consistent trend of higher prevalence of cannabis use in younger males.

Another survey was conducted by

Statistics Canada after the legalization of recreational cannabis in October 2018. This quarterly survey conducted in 2019, shows that there is a slight increase in cannabis use among Canadians aged 65 or older as compared to last year. Statistics Canada also states that from midMay to mid-June of 2019, approximately 4.9 million people (16 percent of Canadians) over age 15 , reported using cannabis in the last three months, which is higher as compared to same period last year i.e. about 4.6 million people reported using cannabis (Hager, 2019). Overall, these studies show that cannabis use is prevalent in Canada and it is believed that the legalization of cannabis may influence the trends observed among Canadians.

\section{Cannabis smoking and its potential health} effects

Tasman et al. (2011) defined cannabis smoking as a type of cannabis use which usually involves burning and inhaling vaporized cannabinoids, primarily THC from small pipes, bongs, paper-wrapped joints or tobacco-leaf-wrapped blunts, and other items. Typically, the cannabis is smoked without filter, the butt length is shorter as compared to tobacco smoking and the smoke is at a higher temperature. Furthermore, cannabis smokers inhale more deeply (Tashkin et al., 1991) and hold their breath for longer period (Wu et al., 1988). The smoke or vapours of THC and other cannabinoids get absorbed into the bloodstream via lungs.

Cannabis smoking can have both short term and long-term health effects that can be positive or negative. Cannabis contains THC and cannabidiol (CBD) that affect the functioning of brain and body. THC causes intoxicating effects whereas CBD is not intoxicating but can still have effects on the brain (Government of Canada, 2018). Other acute health effects shown by multiple studies, may include delayed brain activity, anxiety, impaired attention and memory, increased risk of psychotic symptoms, inability to think clearly, and an increased risk of accidents (Hall \& Solowij, 1998) (Oltmanns \& Emery, 2015) (D'Souza et al., 2009). Long-term or heavy exposure to cannabis or THC can have adverse health effects on the biological, physical, mental, and behavioural well-being of a person and may be associated with diseases of the lungs, heart, vasculature, liver and reproductive health (Gordon et al., 2013). Two studies done by Ribeiro and Ind (2016) suggest that chronic cannabis users have an increased rate of respiratory symptoms which may include chronic cough, sputum production, dyspnoea, hoarse voice, chest tightness. It also affects the lung function by increasing the forced vital capacity of lungs and is associated with bullous lung disease, and barotrauma. Moreover, the prolonged use of cannabis can cause chronic bronchitis and airflow obstruction in heavy users (Schwartz, 2018).

There is a concern that cannabis smoking may contribute to cardiovascular diseases. It increases heart rate, supine systolic and diastolic blood pressures and forearm blood flow via increased sympathetic nervous system activity. These events can significantly increase myocardial oxygen demand of the boldy (Franz \& Frishman, 2016). A study was done in U.S. which involved normal healthy people with no history of cardiovascular risks but a recent exposure to marijuana. The study found a temporal relationship between cannabis use and cardiovascular effects such as atrial fibrillation, acute coronary syndromes, ventricular tachycardia, and even sudden death (Rezkalla \& 
Kloner, 2019). However, the current evidence does not appear to be enough to draw a definitive conclusion on effects of marijuana smoking on cardiovascular events. Therefore, more research is needed to better understand its effect on cardiovascular system.

Lastly, cannabis smoking can be associated with reproductive health problems. Multiple studies have shown that mothers who have exposure to marijuana during pregnancy have children with more depression, hyperactivity, and inattention (American College of Obstetricians Gynaecologists Committee on Obstetric Practice, 2015) (Gunn et al., 2016) (Nomura et al., 2010). Therefore, cannabis use before or during pregnancy can result in negative outcomes for both mother and baby. However, more research is needed to determine the risks of cannabis use on pregnant mothers and babies.

\section{Second-hand Cannabis smoke}

Second-hand smoke (SHS), also known as passive smoking involves the inhalation of smoke by persons other than the intended active smoker. Generally, two types of smoke are produced during cannabis smoking: mainstream and side-stream smoke. Mainstream smoke refers to the smoke exhaled by active smokers whereas side-stream smoke comes from the lighted end of a blunt, cigar, or small pipes used for cannabis smoking. Regardless of the type, second-hand smoke contains harmful chemicals that can have potential health effects. The chemical composition of cannabis smoke generally depends on the strain of cannabis and the way it is cultivated.

Studies have shown that the THC content in cannabis has increased from $4 \%$ in 1995 to over 13\% THC in some cultivated strains (Leung, 2011). In an experimental study conducted by Moir and his colleagues (2007), the smoke composition of both mainstream and side-stream cannabis smoke and tobacco cigarette smoke were compared. Although both cannabis and tobacco contain many similar toxins, the results show up to 20 -fold greater ammonia levels in mainstream cannabis smoke as compared to tobacco smoke. Moreover, the concentration of hydrogen cyanide, $\mathrm{NO}, \mathrm{NO}_{\mathrm{x}}$ and some other aromatic amines was found 3-5 times higher in cannabis smoke. Also, the concentration of polycyclic aromatic hydrocarbons was greater in side-stream cannabis smoke than tobacco smoke. This study confirmed the presence of known carcinogens and other potentially harmful chemicals in both the mainstream and side-stream cannabis smoke. Since the results have shown a higher concentration of chemicals in cannabis smoke than tobacco smoke and it has been established that non-smokers exposed to second-hand tobacco smoke are at $30 \%$ increased risk of cerebral vascular attack (Malek et al., 2015), that can affect cognitive function (Heffernan \& O’Neill, 2013) and future dependence (Fredrick et al., 2011), research is needed to determine if cannabis smoke has more harmful health effects than tobacco smoke or if populations at-risk such as children, immunocompromised populations, and people with respiratory problems have more detrimental health effects when exposed to SHCS.

In fact, a study was done in Australia to understand the health effects of SHCS exposure on community nurses (Iglesias et al., 2018). Recreational cannabis use was not legal at the time of study and cannabis was only used for medical purposes. As smoking is the most common route of medicinal cannabis administration, these nurses were regularly exposed to SCHS as they dealt with patients who used cannabis for therapeutic purposes. The study showed that the nurses exposed to SCHS had an increased risk of cardiovascular diseases, altered cognitive function that may have increased the risk of medical errors, deleterious 
effects on the fetus if nurse was pregnant, and, lastly, a risk of drug addiction. Since Canada has legalized cannabis use for medicinal and recreational purposes, people in Canada may have more frequent exposure to SHCS which may pose similar health effects.

Besides potential health effects, the dank smell of cannabis smoke is considered as a problem in public. People who live in apartments and condominiums often experience odour problems due to shared housing and ventilation.

\section{Legislation}

In Canada, recreational cannabis use is regulated under the Cannabis Act and its companion legislation Bill C-46, an Act to amend Criminal Code. This Act has written prohibitions, obligations and offences and it regulates the use, production, promotion, packing and displaying, selling and distributing of cannabis and cannabis products. The purpose of this Act is to protect public health and ensure public safety (Cannabis Act, 2018). Many regulations are made under this Act to ensure that cannabis use is properly monitored.

Cannabis use is also regulated at provincial and municipal levels. In BC, cannabis use is regulated by four laws i.e. Cannabis Control and Licensing Act, Cannabis Licensing Regulation, Cannabis Control Regulation and Cannabis Control and Licensing Transitional Regulation. The Cannabis Control and Licensing Act enhances some of the legislation provided by federal government and deals with cannabis use for recreational purposes (Cannabis Control and Licensing Act, 2018). The Cannabis Licensing Regulation deals primarily with the selling of cannabis and different types of licenses (Cannabis Licensing Regulation, 2018). Similarly, the Cannabis Control and Licensing Transitional Regulation provides information legislation to regulate cannabis production
(Cannabis Control and Licensing Transitional Regulation, 2018). The Cannabis Control Regulation provides information about sale, supply and possession of cannabis, prohibitions and exemptions of medical vs non-medical cannabis consumption in public. According to this regulation, smoking or vaping cannabis is prohibited in provincial, municipal and regional parks, indoors, near doorways, windows or air intakes, vehicles, boats, schools, near bus stops, public patio etc. The minimum prescribed distance is $6 \mathrm{~m}$ away from the restricted areas. However, people who consume cannabis for medical purposes are exempted from these prohibitions (Cannabis Control Regulation, 2019). Municipal bylaws and the Violation Ticket Administration and Fines Regulation authorize enforcement officers to issue violation tickets if noncompliance with the legislation is observed.

Although the legislation does not permit smoking cannabis in restricted areas, people are still found smoking in outdoor public events, all-age family events, social gatherings, sidewalks, and in public places, exposing the general public to SHCS. One reason could be the adoption of two different sets of rules in the legislation for cannabis consumption i.e. medical vs non-medical. For example, if a person is smoking cannabis at a bus stop, an enforcement officer may assume that it is for medical purposes and not interrogate as they are exempted from the prohibition. Secondly, interrogating every single person smoking cannabis in restricted areas is more tedious, demanding and time-consuming when double standards exist in legislation. This may result in unwanted SHCS exposure to the general public. Until the long-term health effects of SHCS are well known, this topic may not be taken seriously. However, by analyzing its short term/immediate health impacts and/or concerns people may have, a base-line study can be obtained to guide researchers, physicians and 
public health professionals for further research into the topic. Moreover, it can help in implementing initiatives to educate people about health risks associated with cannabis smoking and exposure to SHCS. Also, new policies and amendments in existing policies can be made to protect people from risks of SHCS exposure.

\section{Purpose of the Study}

The purpose of this study was to examine the perceived immediate health impacts and/or concerns from exposure to second-hand cannabis smoke among $\mathrm{BC}$ population who differ in smoking status, gender, educational level and age group. In answering the research question, it can be determined if any group is at higher risk of experiencing health effects. Moreover, a base-line study can be obtained to guide physicians, researchers, policy makers, and public health professionals in taking initiatives to protect people from any negative health effects of second-hand cannabis smoke.

\section{Materials and Methods}

For the purpose of this study, an online survey was drafted using Microsoft Word 2019 Software (Microsoft word, 2019). The survey was then designed and conducted through a BCIT server of SurveyMonkey, an online survey platform (SurveyMonkey, 2019). It consisted of three sections. The first section covered demographic information, the second section was based on exposure to second-hand cannabis smoke and the last section had questions on perceived immediate health impacts and/or concerns about second-hand cannabis smoke. The majority of questions provided in this survey were closed-ended as they are easier to analyze. However, a few openended questions were also a part of this survey as they provide a better understanding of people's perception on certain issues related to SHCS, for example, perception on long-term effects of exposure to SHCS. The questions were designed to be easily understood by the general public and relevant to the purpose of the study (Statistics Canada, 2015).

After creating the survey, it was then distributed publicly via Reddit, Facebook, Instagram and other social media apps. The responses were collected for one week, starting from January 9 to January 16, 2020. Participants were British Columbia residents who had lived in B.C. for at least 12 months. In addition to that, if the participant was cannabis-user, he/she must be at least 19 years or older. There was no age limit for participants who were not cannabis users. The study excluded anyone who did not meet these requirements as the study was only interested in B.C. residents who might have been exposed to second-hand cannabis smoke in the 12 months following the legalization of recreational cannabis in October 2018.

The survey took approximately 3-5 minutes to complete and responses were collected automatically in real-time via SurveyMonkey. The collected data was then exported to Microsoft Excel 2019 Software (Microsoft Excel, 2019) and analyzed using Real Statistics (Real Statistics, 2019).

\section{Results}

\section{Descriptive Data and Statistics}

Since the survey included both demographic information and multiple-choice questions, the data collected for this survey is non-numerical nominal and ordinal data. The majority of questions were closed-ended. Nominal data collected was multi-chotomous, for example, gender and age. Ordinal data included highest level of education. Gender, age, level of education, and cannabis-user status were the demographic information extracted from the 
159 applicable surveys. The information was taken from the raw data and is depicted in graphical formats. All descriptive statistics were exported using the export function of SurveyMonkey (Survey Monkey, 2019).

By gender $46 \%$ of participants $(\mathrm{N}=73)$ were female, $50 \%(\mathrm{~N}=80)$ male, $2 \%(\mathrm{~N}=3)$ Other and $2 \%(\mathrm{~N}=3)$ preferred not to answer (Figure 1).

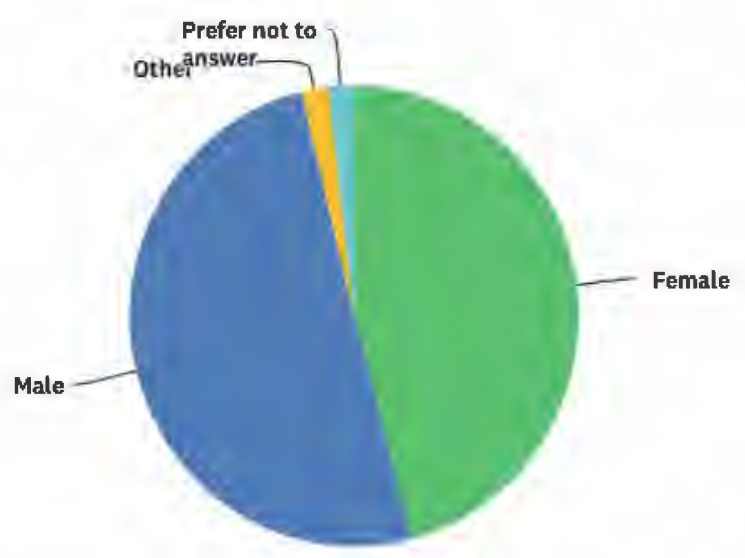

Figure 1: Gender distribution

Distribution by age group was as follow: $5 \%(\mathrm{~N}=7)<19$ years old, $73 \%(\mathrm{~N}=116) 19-28$ years old, $13 \%(\mathrm{~N}=21) 29-38$ years old, $4 \%(\mathrm{~N}=$ 7) $39-48$ years old, $3 \%(\mathrm{~N}=4) 49-58$ years old, $1 \%(\mathrm{~N}=2)>58$ years old and $1 \%(\mathrm{~N}=2)$ preferred not to answer (Figure 2).

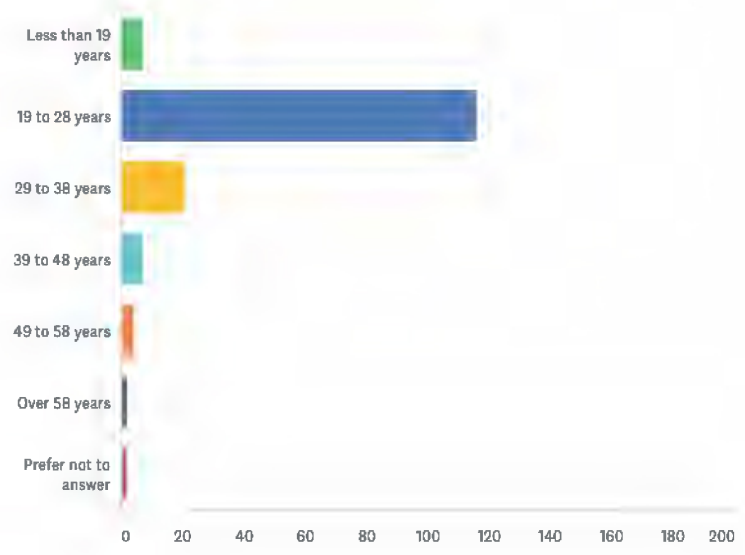

Figure 2: Age distribution
In terms of education, less than $2 \%(\mathrm{~N}=$ 3) had a high school degree, $11 \%(\mathrm{~N}=18)$ had a high school degree or equivalent, $31 \%(\mathrm{~N}=50)$ finished some college but did not complete a degree, $11 \%(\mathrm{~N}=18)$ had an associate degree, $31 \%(\mathrm{~N}=49)$ a bachelor's degree, $8 \%(\mathrm{~N}=12)$ a post graduate degree, $3 \%(\mathrm{~N}=5)$ responded Other and $3 \%(\mathrm{~N}=4)$ preferred not to answer (Figure 3).

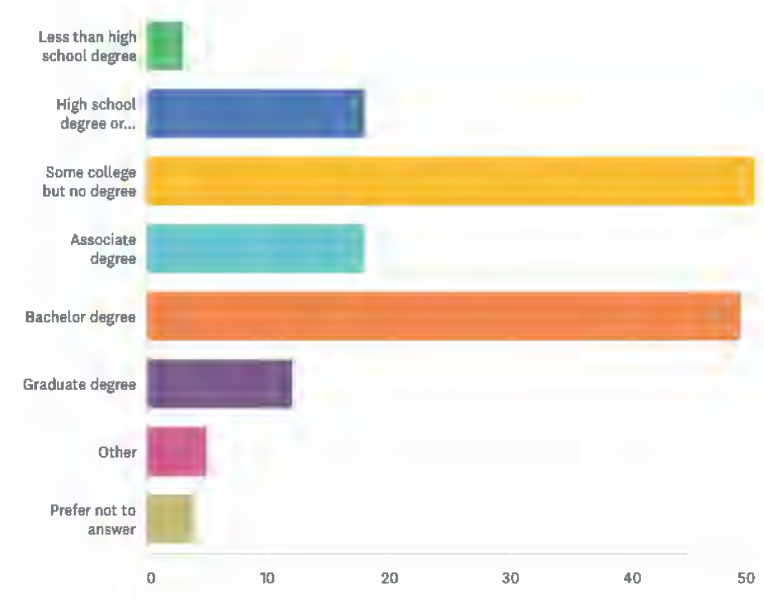

Figure 3: Highest completed education level

Status for cannabis use consisted of $37 \%$ $(\mathrm{N}=58)$ cannabis-users, $60 \%(\mathrm{~N}=96)$ noncannabis users and $3 \%(\mathrm{~N}=5)$ preferred not to answer (Figure 4).

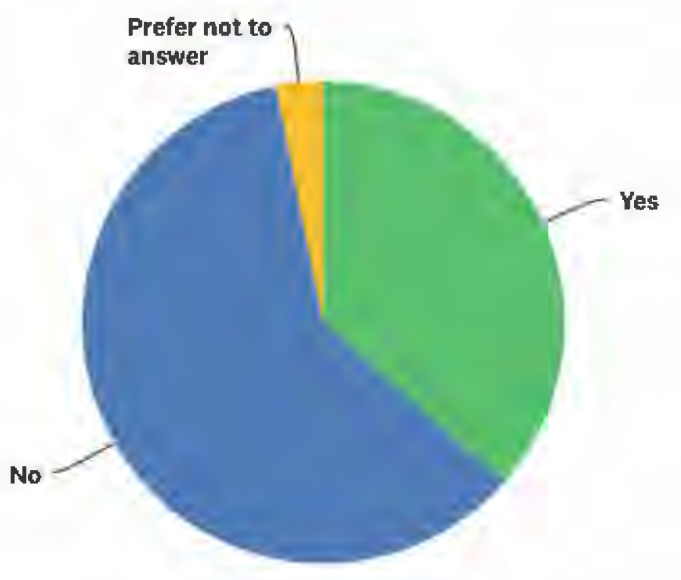

Figure 4: Distribution based on cannabis use 
Also, $40 \%(\mathrm{~N}=59)$ of the participants

believed that exposure to SHCS can have longterm health effects while $38 \%(\mathrm{~N}=55)$ were unsure about the long-term health impacts of exposure to SHCS. $29 \%(\mathrm{~N}=46)$ believed that long-term exposure to SHCS can cause lung cancer and respiratory diseases.

Moreover, the majority of participants, $70 \%$, ( $\mathrm{N}=98)$ believed that they generally get exposed to SHCS on sidewalks, while $43 \%$ (N= $60)$ considered outdoor public events, $40 \%(\mathrm{~N}=$ 56) social gatherings and $30 \%(\mathrm{~N}=42)$ restricted areas such as indoor public places, bus stops, sky train stations or workplaces, as the place of exposure.

\section{Results of Inferential Statistics}

Chi-Square tests compare the frequencies or proportions in two or more groups, hence, used to test hypothesis for this study (Heacock \& Chen, 2019b). The probability, $p=0.05$ was used as a cut off for hypothesis testing. All inferential statistics was analyzed using Real Statistics (Real Statistics, 2019).

Following hypotheses were tested and analyzed:

\begin{tabular}{|c|c|c|c|c|}
\hline & $H_{0}$ and $H_{A}$ & Test used & Result & Conclusion \\
\hline 1. & $\begin{array}{l}\mathbf{H}_{0} \text { : There is no association } \\
\text { between exposure to SHCS and } \\
\text { perceived immediate health } \\
\text { impacts experienced by BC } \\
\text { residents. } \\
\mathbf{H}_{\mathrm{A}} \text { : There is an association } \\
\text { between exposure to SCHS and } \\
\text { perceived immediate health } \\
\text { impacts experienced by BC } \\
\text { residents. }\end{array}$ & $\begin{array}{l}\text { Chi-square } \\
\text { test }\end{array}$ & $\begin{array}{l}P= \\
0.0000015\end{array}$ & $\begin{array}{l}\text { Reject } \mathrm{H}_{0} \text { and conclude that } \\
\text { there is a statistically significant } \\
\text { association between exposure to } \\
\text { SHCS and perceived immediate } \\
\text { health impacts experienced by } \\
\text { BC residents. People who } \\
\text { become exposed to SHCS are } \\
\text { less likely to experience } \\
\text { perceived immediate health } \\
\text { impacts. }\end{array}$ \\
\hline 2. & $\begin{array}{l}\mathbf{H}_{\mathbf{0}} \text { : There is no association } \\
\text { between the place of exposure to } \\
\text { SHCS and perceived immediate } \\
\text { health impacts experienced by BC } \\
\text { residents. } \\
\mathbf{H}_{\mathrm{A}} \text { : There is an association } \\
\text { between the place of exposure to } \\
\text { SHCS and perceived immediate } \\
\text { health impacts experienced by BC } \\
\text { residents. }\end{array}$ & $\begin{array}{l}\text { Chi-square } \\
\text { test }\end{array}$ & $\mathrm{P}=0.15$ & $\begin{array}{l}\text { Do not reject } \mathrm{H}_{0} \text { and conclude } \\
\text { that there is no association } \\
\text { between the place where a } \\
\text { person is exposed to SCHS and } \\
\text { the perceived immediate health } \\
\text { impacts experienced associated } \\
\text { with SHCS. Therefore, people } \\
\text { are equally likely to experience } \\
\text { perceived immediate health } \\
\text { impacts regardless of the place } \\
\text { of exposure. }\end{array}$ \\
\hline 3. & $\begin{array}{l}\mathbf{H}_{0} \text { : There is no association } \\
\text { between the age group and } \\
\text { perceived immediate health } \\
\text { impacts experienced by BC } \\
\text { residents. }\end{array}$ & $\begin{array}{l}\text { Chi-square } \\
\text { test }\end{array}$ & $\mathrm{P}=0.31$ & $\begin{array}{l}\text { Do not reject } \mathrm{H}_{0} \text { and conclude } \\
\text { that there is no association } \\
\text { between the age of a person and } \\
\text { the perceived immediate health } \\
\text { impacts associated with SHCS. }\end{array}$ \\
\hline
\end{tabular}




\begin{tabular}{|c|c|c|c|c|}
\hline & $\begin{array}{l}\mathbf{H}_{\mathrm{A}}: \text { There is an association } \\
\text { between the age group and } \\
\text { perceived immediate health } \\
\text { impacts experienced by BC } \\
\text { residents. }\end{array}$ & & & $\begin{array}{l}\text { All age-groups are equally likely } \\
\text { to experience the perceived } \\
\text { immediate health impacts. }\end{array}$ \\
\hline 4. & $\begin{array}{l}\mathbf{H}_{0}: \text { There is no association } \\
\text { between gender and perceived } \\
\text { immediate health impacts } \\
\text { experienced by BC residents. } \\
\mathbf{H}_{\mathrm{A}} \text { : There is an association } \\
\text { between gender and perceived } \\
\text { immediate health impacts } \\
\text { experienced by BC residents. }\end{array}$ & $\begin{array}{l}\text { Chi-square } \\
\text { test }\end{array}$ & $\mathrm{P}=0.01$ & $\begin{array}{l}\text { Reject } \mathrm{H}_{0} \text { and conclude that } \\
\text { there is a statistically significant } \\
\text { association between males and } \\
\text { females and the perceived } \\
\text { immediate health impacts } \\
\text { associated with SHCS. Females } \\
\text { are more likely to experience the } \\
\text { perceived immediate health } \\
\text { impacts. }\end{array}$ \\
\hline 5. & $\begin{array}{l}\mathbf{H}_{0} \text { : There is no association } \\
\text { between the status of cannabis } \\
\text { user and perceived immediate } \\
\text { health impacts experienced by BC } \\
\text { residents. } \\
\mathbf{H}_{\mathrm{A}} \text { : There is an association } \\
\text { between the status of cannabis } \\
\text { user and perceived immediate } \\
\text { health impacts experienced by BC } \\
\text { residents. }\end{array}$ & $\begin{array}{l}\text { Chi-square } \\
\text { test }\end{array}$ & $\begin{array}{l}\mathrm{P}= \\
0.00003\end{array}$ & $\begin{array}{l}\text { Reject } \mathrm{H}_{0} \text { and conclude that } \\
\text { there is a statistically significant } \\
\text { association between the status of } \\
\text { cannabis user and the perceived } \\
\text { immediate health impacts } \\
\text { associated with SHCS. Non- } \\
\text { cannabis users are more likely to } \\
\text { experience the perceived } \\
\text { immediate health impacts than } \\
\text { cannabis users. }\end{array}$ \\
\hline 6. & $\begin{array}{l}\mathbf{H}_{0}: \text { There is no association } \\
\text { between the level of education of } \\
\text { BC residents and having concerns } \\
\text { with SHCS } \\
\mathbf{H}_{\mathrm{A}} \text { : There is an association } \\
\text { between the level of education of } \\
\text { BC residents and having concerns } \\
\text { with SHCS. }\end{array}$ & $\begin{array}{l}\text { Chi-square } \\
\text { test }\end{array}$ & $\mathrm{P}=0.10$ & $\begin{array}{l}\text { Do not reject } \mathrm{H}_{0} \text { and conclude } \\
\text { that there is no association } \\
\text { between the level of education } \\
\text { and the concerns associated with } \\
\text { SHCS. People with different } \\
\text { level of education are equally } \\
\text { likely to have concerns with } \\
\text { SHCS. }\end{array}$ \\
\hline 7. & $\begin{array}{l}\mathbf{H}_{0} \text { : There is no association } \\
\text { between the gender of BC } \\
\text { residents and having concerns } \\
\text { with SHCS. } \\
\mathbf{H}_{\mathrm{A}} \text { : There is an association } \\
\text { between the gender of BC } \\
\text { residents and having concerns } \\
\text { with SHCS. }\end{array}$ & $\begin{array}{l}\text { Chi-square } \\
\text { test }\end{array}$ & $\mathrm{P}=0.50$ & $\begin{array}{l}\text { Do not reject } \mathrm{H}_{0} \text { and conclude } \\
\text { that there is no association } \\
\text { between the gender and the } \\
\text { concerns associated with SHCS. } \\
\text { Both males and females are } \\
\text { equally likely to have concerns } \\
\text { associated with SHCS. }\end{array}$ \\
\hline
\end{tabular}




\section{Discussion}

The purpose of this study was to examine perceived short-term health impacts or concerns from exposure to SHCS. Seven hypotheses were tested to determine associations between health impacts and/or concerns of SHCS and the following demographic variables: gender, age, smoking status and education level of $\mathrm{BC}$ residents. The majority of survey participants were young adults i.e. 19 to 28 years old, non-cannabis users, and had some college education or a bachelor's degree. Therefore, the results from this study will be best extrapolated to individuals in these three categories. The findings of this study agreed with previous research suggesting that there is a lack of sufficient data to determine the health effects of exposure to SHCS.

Inferential analysis of data using the Chi-square test shows that there is no association between exposure to SHCS and perceived immediate health impacts experienced by people. In fact, the results show that people who become regularly exposed to SHCS are less likely to experience any perceived immediate health impacts. These findings are not consistent with previous research studies and it could be due to the legalization of cannabis for recreational use being so recent (Iglesias et al., 2018). As such, these gaps are expected to be filled in, with future research. However, the results also showed that 41 out of 139 participants (30\%) experienced headaches, coughing, chest tightness and irritation to eyes after exposure to SHCS. These results are consistent with past research studies which showed that short-term exposure to SHCS can result in altered cognitive functions, headache, delayed brain activity and disruption in functioning of lungs (Hall \& Solowij, 1998) (Oltmanns \& Emery, 2015) (D'Souza et al.,
2009) (Schwartz, 2018). As THC causes intoxicating effects (Government of Canada, 2019), the presence of THC and its concentration in SHCS could have resulted in these health impacts. Moreover, the presence of known carcinogens and other potentially harmful chemicals in both the mainstream and side-stream cannabis smoke can also affect cognitive function (Heffernan \& O'Neill, 2013). However, more research is needed to better understand the cause of these health effects. For those who did not experience any perceived immediate health impacts after constant exposure to SHCS, health impacts may vary depending on the duration of exposure, concentration of SHCS, or underlying health conditions. People who become exposed to SHCS for longer periods of time or at higher concentrations are more likely to experience perceived immediate health impacts as compared to short term exposure or exposure to SHCS at low concentrations, respectively. As discussed earlier, the legalization of cannabis for recreational use is very recent, which could mean that people are not exposed to a concentration of SHCS that could result in any health impacts. Again, further research is needed to better understand these results.

Other than that, the Chi-square test also showed that people, regardless of their age and place of exposure to SHCS, are equally likely to experience perceived immediate health impacts. As cannabis for recreational use and secondhand cannabis smoking are still emerging topics, there were no past studies on the health effects of SHCS based on age or place of exposure to SHCS. However, considering the large proportion of participants being in early adulthood i.e. 19 to 28 years old, the results were mainly demonstrated by that age-group, therefore, not showing any variations in health impacts based on age. Similarly, the majority of 
people were exposed to SHCS on sidewalks, which could mean that the people were exposed to similar levels of SHCS or concentration of chemicals present in SHCS that is generally present on sidewalks. This may have led to consistent results after exposure to SHCS. Moreover, the perceived immediate health impacts depend on the concentration of SHCS present in a place rather than the place itself, which could also explain why people are equally likely to experience perceived immediate health impacts regardless of the place of exposure. However, there is a scope for more research.

Although the findings of this study show that age and place of exposure do not affect the likelihood of experiencing perceived immediate health impacts, chi-square tests concluded that females and non-users are more likely to experience perceived immediate health impacts as compared to males and cannabis users, respectively. As mentioned earlier, cannabis smoking is a very new topic. As a result, minimal research has been conducted to examine the sensitivity of SHCS on females and nonusers. However, the findings from a previous study showed that nurses exposed to SCHS had an increased risk of cardiovascular diseases, altered cognitive function that may have increased the risk of medical errors, deleterious effects on the fetus if the nurse was pregnant, and, lastly, a risk of drug addiction (Iglesias et al., 2018). These findings can be correlated with the findings of this study as females seem to be more sensitive and showed health impacts. However, these findings can only be confirmed in future, once enough research is completed on the grey areas.

Other than perceived immediate health impacts, both cannabis and non-cannabis users believe that exposure to SHCS can have long-term health effects. A majority of the participants think that long-term exposure to SHCS can lead to lung cancer and other respiratory diseases. Studies done in past also show similar results as the findings of these studies showed that long-term exposure to SHCS is associated with diseases of the lungs, heart, vasculature, liver and reproductive health (Gordon et al., 2013) (Ribeiro \& Ind, 2016) (Schwartz, 2018) (Rezkalla \& Kloner, 2019) (American College of Obstetricians Gynaecologists Committee on Obstetric Practice, 2015) (Gunn et al., 2016) (Nomura et al., 2010). However, more research is needed in future to determine the long-term health effects of cannabis smoke among British Columbians.

The findings of this study also suggest that regardless of gender or level of education, participants expressed other concerns with SHCS besides the health effects. This could mean that both males and females as well as people with different levels of education share similar concerns associated with SHCS. The participants mentioned exposure of young children to SHCS and smell of cannabis smoke as two main concerns. Many other minor concerns include less stringent laws for cannabis smoking and the need of strict enforcement of laws. Although these results were not analyzed by the author, with the legalization of cannabis for recreational use, there is a risk that more and more people will have similar concerns in future. Therefore, there is a need for government to focus on these concerns and come up with strategies that could help addressing the problem at its initial stage.

The results obtained from this study were as expected, implying that there is an inadequate scientific knowledge regarding the long-term health effects from exposure to SHCS as well as the variation in health effects among different age groups, gender, smoking status and place of exposure. However, the findings of this study agreed with previous research on shortterm health effects, suggesting that exposure to SHCS could possibly result in headaches, coughing, chest tightness and irritation to eyes. Additional information that could be derived 
from this study is the two main concerns people have regarding SHCS, exposure of young children to SHCS and the odour of cannabis smoke.

\section{Knowledge Translation and Recommendations}

The findings of this research paper show that people who are exposed to SHCS are not very likely to experience perceived immediate health impacts. This could mean that over time, people become less sensitive to SHCS and can potentially expose themselves to higher concentration of SHCS, which could result in adverse long-term health effects. Although the long-term health effects are not well known, the results from this study regarding perceived immediate health impacts can be used as a baseline study to guide researchers to identify potential short-term health impacts on people. The study shows that headaches, coughing, chest tightness and irritation to eyes are few shortterm perceived health impacts. Physicians and other health care professionals can use it as a guide to educate people on SHCS and ensure public safety. The results also show that everyone is equally likely to experience perceived immediate health impacts regardless of the place of exposure and the age of a person. This information could also be used to educate people as young populations generally assume that they are not at high risk. BC legislation has already prohibited smoking cannabis in restricted areas, however considering the findings of this study which states that place of exposure is not a key factor in experiencing health impacts, more policies and amendments in existing policies can be made to minimize unintentional exposure to SHCS, even on sidewalks and other unrestricted areas. As many people have concerns about less stringent laws and need of strict enforcement, the government can enforce the laws more rigorously to ensure that cannabis users are well aware of them. Also, initiatives can be taken to educate both cannabis users as well as non-users about the potential risks associated with exposure to SHCS as well as existing laws and educational resources so that everyone can play a role in building a safer community and reduce any potential risks associated with exposure to SHCS.

\section{Limitations}

Lack of time was the main limitation for this research study. As limited time was provided to conduct this research study, the author chose to conduct an online survey only. As a result, predominantly a younger population participated in the survey; in part, because they were more likely to be contacts (or their contacts) of the researcher. Also, the survey was only open for two weeks and only received responses from 159 participants. However, in the pilot study, both online and in-person surveys were conducted, and it showed more active participation from both young and older populations. Also, a large portion of time was spent on the process to get approval from the BCIT Research Ethics Board to ensure that the research abides by all the ethical considerations. Another limitation for this study was money. Insufficient funding was available to carry out the research, which was another reason for choosing online surveys.

\section{Future Research}

A follow-up study can be conducted to determine if the results are still consistent and whether people experience any short-term or long-term health impacts.

Both online and in-person surveys can be conducted to reach out to a larger demographic and identify whether people from 
different age groups, genders or of dissimilar smoking status have different perceived immediate health impacts from exposure to SHCS.

Also, a study can be performed to examine the level of knowledge people have about existing laws, policies, and educational resources, as well as any health effects associated with cannabis since the legalization of cannabis for recreational purposes.

A similar study can also be carried out to compare the level of knowledge among cannabis-users vs non-users about cannabis. If possible, a comparison and correlation between long-term health effects of tobacco vs cannabis smoke can be examined in future.

\section{Conclusion}

As cannabis has been legalized in Canada for recreational purposes, it is likely that more people will be smoking cannabis in the future. With an increasing number of cannabis smokers, the risk of becoming exposed to SHCS will also increase. The findings of this study identified a few perceived immediate health impacts associated with SHCS such as headaches, coughing, chest tightness and eye irritation. With the increase in exposure, people will more likely be exposed to high levels of SHCS. This may result in adverse health impacts. As long-term health effects are not yet known, precautionary steps should be taken now to minimize its ill-effects in future. The government should provide tools to aide researchers and health care professionals to conduct an in-depth research on SHCS and its health effects. Moreover, initiatives should be taken to educate general public about cannabis smoke, its composition and associated health effects. The government should also come up with policies to enforce and minimize unnecessary exposure to SHCS.

\section{Acknowledgements}

The authors would like to thank the British Columbia Institute of Technology Environmental Health Department for supporting their research. Additionally, a special thank you to everyone who participated in the study.

\section{Competing Interest}

The authors declare that they have no competing interests

\section{References}

American College of Obstetricians Gynaecologists Committee on Obstetric Practice (2015). "Committee Opinion No. 637: Marijuana Use During Pregnancy and Lactation". Obstetrics and Gynaecology. 126 (1): 234-8. doi: 10.1097/01.AOG.0000467192. 89321.a6. PMID 26241291.

Cannabis Control Regulation, BC Reg 204/2018. Retrieved from http://www.bclaws.ca/civix/document/id /complete/statreg/204 2018

Cannabis Licensing Regulation, BC Reg 202/2018. Retrieved from http://www.bclaws.ca/civix/document/id /complete/statreg/202 2018

Cannabis Control and Licensing Transitional Regulation, BC Reg 203/2018.

Retrieved from http://www.bclaws.ca/civix/document/id /complete/statreg/203 2018

Cannabis Control and Licensing Act, SBC 2018, c. 29. Retrieved from http://www.bclaws.ca/civix/document/id /complete/statreg/18029 
Cannabis Act, SC 2018, c. 16. Retrieved from https://laws.justice.gc.ca/eng/acts/C24.5/page-1.html

D'Souza, D.C., Sewell, R.A., Ranganathan, M., (2009). Cannabis and psychosis/schizophrenia: human studies. European Archives of Psychiatry and Clinical Neuroscience. 259 (7): 413-31.

Franz, C.A., \& Frishman, W.H. (2016). Marijuana use and cardiovascular disease. Cardiology in Review, 24(4), 158-162. doi:10.1097/CRD.0000000000000103

Gordon, A.J., Conley, J.W., Gordon, J.M., (2013). Medical consequences of marijuana use: a review of current literature. Current Psychiatry Reports. 15(12): 419.

Government of Canada. (2018). Cannabis health effects. Retrieved from https://www.canada.ca/en/healthcanada/services/drugsmedication/cannabis/healtheffects/effects.html

Gunn, J.K., Rosales, C.B., Center, K.E., Nuñez, A., Gibson, S.J., Christ, C., Ehiri, J.E., (2016). Prenatal exposure to cannabis and maternal and child health outcomes: a systematic review and meta-analysis. BMJ Open. 6 (4): e009986. doi:10.1136/bmjopen-2015-009986. PMC 4823436. PMID 27048634.

Hager, M. (2019). Seniors report more cannabis use since legalization: StatsCan survey found Canadians aged 65 or older were the only age group to show an increase in marijuana use. The Globe and Mail.

Hall, W., Solowij, N., (1998). Adverse effects of cannabis. Lancet. 352(9140):1611-6.

Heacock, H. \& Chen, D. (2019b). ENVH 8400

Research Methods Module 4B: ChiSquare Test. [PowerPoint slides]. Retrieved from https://learn.bcit.ca/d21/le/content/56988 4/viewContent/3947395/View

Heffernan, T.M. and O’Neill, T.S. (2013). Exposure to second-hand smoke damages everyday prospective memory. Addiction, 108(2): 420-426.

Iglesias, M.A., Pertile, J., Molloy, L. \& Chan, A. (2018). The effects and impact of second-hand cannabis smoke exposure on nurses working in the community. Australian Nursing and Midwifery Journal, 26(4), 20-23.

Leung, L. (2011). Cannabis and its derivatives: review of medical use. The Journal of the American Board of Family Medicine, 24(4), 452-462.

Malek, A.M., Cushman, M., Lackland, D.T., Howard, G. and McClure, L.A. (2015). Second-hand smoke exposure and stroke. The reasons for geographic and racial differences in stroke (REGARDS) study. American Journal of Preventive Medicine, 49(1): e89-e97.

Microsoft Excel. (2019). Microsoft Excel Software. Retrieved from https://www.office.com/launch/excel?ui $=$ en-US\&rs $=$ CA\&auth $=2$

Microsoft Word. (2019). Microsoft Word Software.

Moir, D., Rickert, W. S., Levasseur, G., Larose, Y., Maertens, R., White, P., \& Desjardins, S. (2007). A comparison of mainstream and side stream marijuana and tobacco cigarette smoke produced under two machine smoking conditions. Chemical research in toxicology, 21(2), 494-502

Nomura, Y., Marks, D.J., Halperin, J.M., (2010). Prenatal exposure to maternal and paternal smoking on attention deficit hyperactivity disorders symptoms and diagnosis in offspring. The Journal of nervous and mental disease. 198 (9): 672-8. 
doi:10.1097/NMD.0b013e3181ef3489.

PMID 20823730.

NIDA. (2019). Marijuana. Retrieved from https://www.drugabuse.gov/publications /drugfacts/marijuana

Oltmanns, T., Emery, R. (2015). Abnormal Psychology. New Jersey: Pearson. 978(42): 294.

Real Statistics. (2019). Real Statistics Software. Retrieved from http://www.realstatistics.com/real-statisticsenvironment/supplemental-dataanalysis-tools/

Rezkalla, S., \& Kloner, R. A. (2019). Cardiovascular effects of marijuana. Trends in cardiovascular medicine, 29(7), 403-407. doi: 10.1016/j.tcm.2018.11.004

Ribeiro, L., \& Ind, P. (2016). P147 Effect of cannabis smoking on respiratory symptoms and lung function: A structured literature review. Thorax, 71(Suppl 3), A163-A163. doi:10.1136/thoraxjnl-2016-209333.290

Ribeiro, L. I., \& Ind, P. W. (2016). Effect of cannabis smoking on lung function and respiratory symptoms: A structured literature review. NPJ Primary Care Respiratory Medicine, 26(1), 16071. doi:10.1038/npjpcrm.2016.71

Rosenthal, E. (2002). Ask Ed: Marijuana Gold: Trash to Stash. Perseus Books Group. p. 15.

Rotermann, M., \& Macdonald, R. (2018). Analysis of trends in the prevalence of cannabis use in Canada, 1985 to 2015. Health Reports, 29(2), 10-20.

Rotermann, M., \& Pagé, M. (2018). Prevalence and correlates of non-medical only compared to self-defined medical and non-medical cannabis use, Canada, 2015. Health Reports, 29(7), 3-13.

Schultz, R. E. (1973). Man, and marijuana. Natural History 82: 59-68, 78, 82.

Schwartz, D. A. (2018). Cannabis and the lung. International Journal of Mental Health and Addiction, 16(4), 797-800. doi:10.1007/s11469-018-9902-z

Statistics Canada. (2015). Questionnaire Design. Retrieved from https://www150.statcan.gc.ca/n1/pub/12 -539-x/2009001/design-conceptioneng.htm\#archived

SurveyMonkey. (2019). SurveyMonkey Software. Retrieved from https://www.surveymonkey.com

Tashkin, D. P. et al. (1991). Tar, CO and delta 9THC delivery from the 1 st and 2 nd halves of a marijuana cigarette. Pharmacol. Biochem. Behav. 40, 657661.

Tasman, A., Kay, J., Lieberman, J.A., First, M.B., \& Maj, M. (2011). Psychiatry. John Wiley \& Sons, 978(119), 9.

Wu, T. C., Tashkin, D. P., Djahed, B. \& Rose, J. E. (1988). Pulmonary hazards of smoking marijuana as compared with tobacco. N. Engl. J. Med. 318, 347-351. 